\title{
Evaluation on post-earthquake reconstruction community landscape facilities with weighted TOPSIS method
}

\author{
Pengyan Jiang ${ }^{1, a}$, Siqi Jiang ${ }^{1, b}$ and Lu Gan ${ }^{1, c}$ \\ ${ }^{1}$ school of Sichuan, Agricultural University, Chengdu 610000, China \\ a1035103164@qq.com, bjsq_396578998@qq.com, cganlu_swe_1119@sina.cn
}

\begin{abstract}
Keywords: weighted TOPSIS method, analytic hierarchy process method, post-earthquake reconstruction, landscape facility.
\end{abstract}

\begin{abstract}
Establish the evaluation and calculation model of post-earthquake reconstruction community landscape facility based on weighted TOPSIS method. Determine each weight of evaluation factor with analytic hierarchy process method. Applying the model on post-earthquake reconstructed Yijie district in Dujiangyan and analyzing the result to verify the model's maneuverability, and provide guiding thought for reconstruction community landscape facilities.
\end{abstract}

\section{Introduction}

With the rapid development of economy, landscape facilities play an increasingly important role in shaping the image of the community. Yang Jianhua evaluated the quality of urban public space landscape facilities with fuzzy comprehensive evaluation method ${ }^{[1]}$.Wang Yaqiong, Song E and Liao Zaiyi researched the Suzhou egret park landscape facilities with fuzzy analytic hierarchy process method. And they put forward the improvement reference method of the post-occupancy urban public space landscape facilities [2]. But there is no evaluation and analysis on post-earthquake reconstruction community landscape facilities' quality. However, it is one of the most important contents of the post-earthquake reconstruction community landscape facilities planning and construction. Only have a correct understanding and evaluation for the quality of post-earthquake reconstruction Community landscape facilities, can we better carry out the planning and design of reconstructed community landscape facilities, then achieve the purpose of enriching people's lives. In this paper, it attempts to evaluate and analyze the quality of the post-earthquake reconstruction community landscape facilities with weighted TOPSIS method, and determine a set of evaluable index system with analyzing literatures, consulting experts, combining with the characteristics of the community landscape facilities and the special factors of the post-disaster reconstruction community. It determines the weight of evaluation index with analytic hierarchy process method and MATLAB software, and then determines the evaluation and calculation model of post-earthquake reconstruction community landscape facilities. It selects three communities in Yijie district of Dujiangyan to carry on the example analysis. The three communities are reconstructed after "5.12" earthquake. The model's purposes are to provide scientific basis and theoretical support for the community landscape facilities' improvement and the landscape facility planning of the post-earthquake reconstruction community.

\section{Model Building}

Evaluation Index System. According to the principle of Kevin Lynch's urban public image and the significance of analogy, community landscape image is the residential community landscape elements which similar to Kevin Lynch's urban public image elements, and it is the public image in people's visual perception ${ }^{[3]}$.So the evaluation factors of community landscape facilities are similar to the evaluation factors of urban public space landscape facilities. After Wenchuan earthquake, some scholars have carried out community awareness research to the earthquake victims on Sichuan. They found that post-disaster residents generally lack sense of community, community responsibility and the sense of community belonging at low level; residents lack community participation ${ }^{[4]}$.The proper setting of landscape facilities can make residents communicate actively, 
increase the participation of community, and enhance the sense of community belonging. Therefore, form the evaluation index system of post-earthquake reconstruction community landscape facilities after adjusting Yang Jinhua's evaluation factors system of landscape facilities and acquiring comments from experts ${ }^{[1]}$. The evaluation index system combines the design principles of community landscape and considering the special factors of the post-earthquake reconstruction community. The evaluation index system is shown in Table 1.

Table 1 Evaluation index system

\begin{tabular}{|c|c|c|c|}
\hline Target layer & Criterion layer & Factors layer. & Number \\
\hline \multirow{7}{*}{ 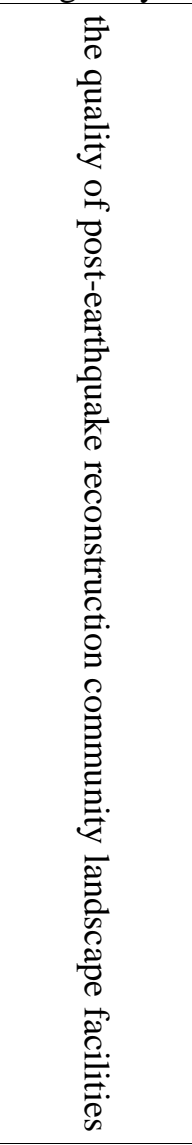 } & $\begin{array}{l}\text { Using function } \\
\text { (A) }\end{array}$ & $\begin{array}{c}\text { The number and spacing rationality of landscape facilities } \\
\text { The convenience and comfort of landscape facilities } \\
\text { The completeness of the landscape facilities system } \\
\text { The accessibility of landscape facilities } \\
\text { The security of landscape facilities }\end{array}$ & $\begin{array}{l}\text { A1 } \\
\text { A2 } \\
\text { A3 } \\
\text { A4 } \\
\text { A5 }\end{array}$ \\
\hline & Artistry (B) & $\begin{array}{l}\text { The form and style of landscape facilities } \\
\text { The scale of landscape facilities } \\
\text { The color richness of landscape facilities }\end{array}$ & $\begin{array}{l}\text { B1 } \\
\text { B2 } \\
\text { B3 }\end{array}$ \\
\hline & Ecology (C) & $\begin{array}{l}\text { Non pollution and renewable of landscape facilities } \\
\text { Low energy consumption of landscape facilities }\end{array}$ & $\begin{array}{l}\text { C1 } \\
\text { C2 }\end{array}$ \\
\hline & Culture (D) & $\begin{array}{l}\text { Regional characteristics of landscape facilities } \\
\text { Time characteristics of landscape facilities }\end{array}$ & $\begin{array}{l}\text { D1 } \\
\text { D2 }\end{array}$ \\
\hline & Sociality (E) & $\begin{array}{c}\text { The excitation of landscape facilities to social activities } \\
\text { The influence of landscape facilities on the sense of } \\
\text { residents' belonging }\end{array}$ & $\begin{array}{l}\text { E1 } \\
\text { E2 }\end{array}$ \\
\hline & $\begin{array}{l}\text { Coordination } \\
\text { (F) }\end{array}$ & $\begin{array}{l}\text { Coordination of landscape facilities and natural environment } \\
\text { Coordination of landscape facilities and space environment } \\
\text { Integrity and continuity of landscape facilities }\end{array}$ & $\begin{array}{l}\text { F1 } \\
\text { F2 } \\
\text { F3 }\end{array}$ \\
\hline & $\begin{array}{l}\text { Management } \\
\text { and } \\
\text { maintenance } \\
(G)\end{array}$ & $\begin{array}{l}\text { Normal use maintenance of landscape facilities } \\
\text { Environmental sanitation maintenance of landscape facilities } \\
\text { Management and operation efficiency of landscape facilities }\end{array}$ & $\begin{array}{l}\text { G1 } \\
\text { G2 } \\
\text { G3 }\end{array}$ \\
\hline
\end{tabular}

\section{The determination of evaluation index weight. ${ }^{[5]}$}

The formation of judgment matrix. It issued questionnaires to Yijie community, Shangyang community and Shangyou community, 30 in all and 26 valid questionnaires were recovered, the rate of recovery is $86.67 \%$. Meanwhile, we invite relevant experts to judge the degree of importance, and the paper established judgment matrix: $A=\left(a_{i j}\right)_{n \times n}$. In order to determine specific values in the judgment matrix, the scale representation of $1 \sim 9$ proposed by T. L. Saaty is used.

\section{The single hierarchical order and inspection}

Step1: calculate the maximum eigenvalue of the judgment matrix: $\lambda \max$.

Step2: calculate the consistent index CI: ${ }^{C I}=\frac{\lambda_{\max }-n}{n-1}$ " $n$ " is the order of the judgment matrix.

Step3: Checking table2 according to different orders in the judgment matrix, we can determine the average random consistent index RI.

Table 2 The average random consistent index RI

\begin{tabular}{|l|l|l|l|l|l|l|l|l|l|}
\hline Matrix order $\mathrm{n}$ & 1 & 2 & 3 & 4 & 5 & 6 & 7 & 8 & 9 \\
\hline RI & 0.00 & 0.00 & 0.58 & 0.90 & 1.12 & 1.24 & 1.32 & 1.41 & 1.45 \\
\hline
\end{tabular}

Step4: calculate the consistent ratio CR and make judgment: When $\mathrm{CR}<0.1$, the consistency of judgment matrix is acceptable, when CR $>0.1$, the consistency of judgment matrix is unacceptable.

Step5: The each column of judgment matrix after normalized approximately reflect the situation 
of weight value distribution, so arithmetic mean value can be used to estimate weight vector.

The totality hierarchical order and inspection End up with various factors, especially the lowest layer of factors on the target weights of sorting, calculate the synthetic weight of each factor for the total target, and Hierarchy total order sorts are checked consistency.

The above steps are implemented in MATLAB and the weight of each evaluation factor is calculated according to the above method and it is showed in Table3.

Table 3 The weight of evaluation factors

\begin{tabular}{|c|c|c|c|c|c|}
\hline $\begin{array}{l}\text { target } \\
\text { layer }\end{array}$ & $\begin{array}{l}\text { criterion } \\
\text { layer }\end{array}$ & $\begin{array}{l}\text { Weight } \\
\text { value }\end{array}$ & $\begin{array}{c}\text { the factor } \\
\text { layer }\end{array}$ & $\begin{array}{l}\text { Weight } \\
\text { value }\end{array}$ & $\begin{array}{l}\text { The total weight of factors } \\
\text { relative to the target layer }\end{array}$ \\
\hline \multirow{7}{*}{ 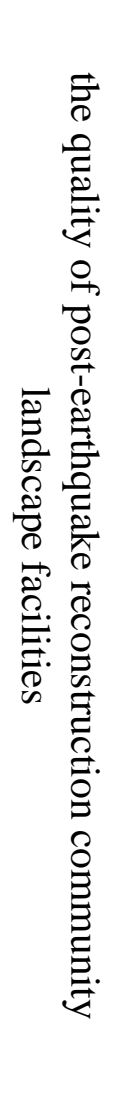 } & A & 0.3543 & $\begin{array}{l}\text { A1 } \\
\text { A2 } \\
\text { A3 } \\
\text { A4 } \\
\text { A5 }\end{array}$ & $\begin{array}{l}0.1655 \\
0.2352 \\
0.1079 \\
0.0668 \\
0.4246 \\
\end{array}$ & $\begin{array}{l}0.0586 \\
0.0833 \\
0.0382 \\
0.0237 \\
0.1504 \\
\end{array}$ \\
\hline & B & 0.1587 & $\begin{array}{l}\text { B1 } \\
\text { B2 } \\
\text { B3 }\end{array}$ & $\begin{array}{l}0.2970 \\
0.5396 \\
0.1634\end{array}$ & $\begin{array}{l}0.0471 \\
0.0856 \\
0.0259\end{array}$ \\
\hline & $\mathrm{C}$ & 0.0448 & $\begin{array}{l}\text { C1 } \\
\text { C2 }\end{array}$ & $\begin{array}{l}0.6667 \\
0.3333\end{array}$ & $\begin{array}{l}0.0299 \\
0.0149\end{array}$ \\
\hline & D & 0.2399 & $\begin{array}{l}\text { D1 } \\
\text { D2 }\end{array}$ & $\begin{array}{l}0.5000 \\
0.5000\end{array}$ & $\begin{array}{l}0.1200 \\
0.1200\end{array}$ \\
\hline & E & 0.0676 & $\begin{array}{l}\text { E1 } \\
\text { E2 }\end{array}$ & $\begin{array}{l}0.6667 \\
0.3333\end{array}$ & $\begin{array}{l}0.0451 \\
0.0225\end{array}$ \\
\hline & $\mathrm{F}$ & 0.0312 & $\begin{array}{l}\text { F1 } \\
\text { F2 } \\
\text { F3 }\end{array}$ & $\begin{array}{l}0.4000 \\
0.4000 \\
0.2000\end{array}$ & $\begin{array}{l}0.0125 \\
0.0125 \\
0.0062\end{array}$ \\
\hline & G & 0.1036 & $\begin{array}{l}\text { G1 } \\
\text { G2 } \\
\text { G3 }\end{array}$ & $\begin{array}{l}0.3333 \\
0.3333 \\
0.3333\end{array}$ & $\begin{array}{l}0.0345 \\
0.0345 \\
0.0345\end{array}$ \\
\hline
\end{tabular}

\section{The evaluation calculation model of weighted TOPSIS method}

Step 1: The same tendency of evaluation index: All the indexes in this research are high quality.

Step 2: Normalization processing: normalization processing the original data matrix after the same tendency was carried out.

Step 3: Determine the optimal vector and the worst vector of the evaluating results: the optimal vector is the maximum of each evaluation index in the normalized vector, and the worst vector is minimum of each evaluation index in the normalized vector.

Step 4: Calculate the distance between the evaluation object and the optimal and the worst point.

Step 5: Calculate the approach degree $\mathrm{Ci}$ between the evaluation objects and the optimal scheme, then compare the size and sorting.

\section{Case Study}

Calculation. Select the Yijie community, Shangyang community, Shangyou community of Yijie district in Dujiangyan as case studies; Yijie district is located in the northeast of Dujiangyan City, and the Puyang River flows on the west and north side as the half annular with a total area of 148.32 hectares. It is a city block model of post-disaster reconstruction that makes housing, schools, health care, shopping, sightseeing and leisure as a whole ${ }^{[6]}$. The study issued 120 questionnaires, 40questionnaires each community, 109 questionnaires were collected, and the recovery rate was $90.83 \%$. The evaluation set of the questionnaire is \{extremely satisfied, very satisfied, satisfied, 
dissatisfied, and extremely dissatisfied $\}$, the corresponding value is $\{5,4,3,2$, and 1$\}$.

Step 1: Establish the evaluation matrix, and normalize the original data to attain the normalized matrix of evaluation factors score.

Step 2: Determine the optional vector and worst vector

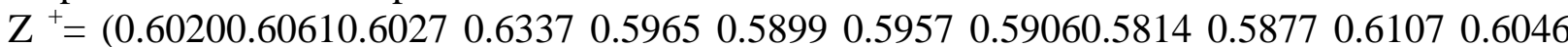

$0.58520 .60120 .58500 .60010 .58360 .59590 .58100 .6216)$

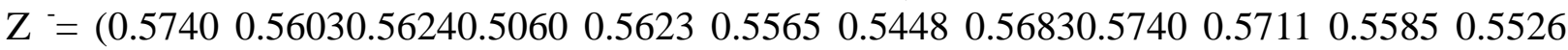

0.56660 .54270 .56210 .55450 .56950 .56610 .57440 .5480 )

Step 3: Calculate the distance of each community and optimal point $\mathrm{D}^{+}$, the distance of each community and worst point $\mathrm{D}^{-}$, and calculate the approach degree $\mathrm{C}_{\mathrm{i}}$ of each community and the optimal value, then sort order, it is showed in table4.

Table 4Theapproach degree $\mathrm{Ci}$ of each community and the optimal value

\begin{tabular}{|c|c|c|c|}
\hline & Shangyou community & Yijie community & Shangyang community \\
\hline $\mathrm{D}+$ & 0.0300 & 0.0216 & 0.0426 \\
\hline $\mathrm{D}-$ & 0.0294 & 0.0407 & 0.0129 \\
\hline $\mathrm{Ci}$ & 0.4948 & 0.6533 & 0.2321 \\
\hline sorting & 2 & 1 & 3 \\
\hline
\end{tabular}

Analysis. TOPSIS method is a common decision-making method in multi-objective decision analysis of system engineering. It ascertains the optimal scheme and worst scheme in finite schemes by determining the normalized value of the original data, and then calculates the approach degree $\mathrm{Ci}$ value of each scheme and the optimal scheme. The range of approach degree $\mathrm{Ci}$ value is between 0 and 1 , and it further to 1 means the evaluation is more close to the optimal level, and vise versa ${ }^{[7]}$.

In this study, it comprehensively evaluates the quality of three community landscape facilities in Yijie district with weighted TOPSIS method. The result shows that the first is Yijie community, the second is Shangyou community and the last is Shangyang community. Combining with field surveys and visiting to community residents, then in-depth analysis found that: Yijie community is built with the help of Shanghai counterparts after Wenchuan earthquake, and its design considers the balance and comprehensiveness in function, art, ecology, etc., Shangyou community is a resettlement community aided by the government after earthquake(except Yanshan bank community ), although the landscape facility planning is considered overall, but the attention degree on the sociality, management and maintenance and other aspects is lower than other aspects; Shangyang community is founded by the bankrupt company--Qingcheng paper mill. The Ci value of Shangyang community is lower, after analyzing, the reason is the facility of Shang Yang community are less variety, less quantity, shabby, old, poor system completeness, and it lacks common facilities such as public toilets, barrier free facilities; In addition, table 4 shows that the value of $\mathrm{Ci}$, even top-ranked Yijie community score is only 0.6533 , and it is far from the optimal value 1 , which shows that the quality of three community landscape facilities is low. In this study, the scores of normal use and safety maintenance, management efficiency, integrity and continuity, system completeness of the landscape facilities are pretty low. It means that Yijie district in the process of improving the community landscape facilities and the planning and setting of community landscape facilities in the future shall pay attention to these aspects.

\section{Conclusion}

Take Yijie district in Dujiangyan as example, in this article, the evaluation model of the post-earthquake reconstruction community landscape facility is initially established based with weighted TOPSIS method. The evaluation model provides a reliable basis for the improvement of the community landscape facilities and the planning and setting of the post-earthquake reconstruction community landscape facilities. In this paper, the number of selected communities is less; the results of evaluation may not be comprehensive; besides, due to the differences of local and economic development level, the evaluation factors and the weight should be adjusted appropriately to make a more scientific evaluation in the specific evaluation in the future. 


\section{Acknowledgements}

All people who made contributions to the article, here together to thank! This article is supported by the Youth Funds of Sichuan Provincial Education Department (Grant NO.14ZB0014), the Key Funds of Sichuan Social Science Research Institution "System Science and Enterprise Development Research" (Grant NO.Xq15B09), and the Humanities Social and Sciences Research Funds of Education Ministry (Grant NO.15XJC630001). The article's corresponding author is Ga Lu.

\section{References}

[1] Yang Jianhua. Fuzzy Syntheses Evaluation Research on the Quality of Environmental Facilities in Urban Public Space [J] Wuhan University of Technology (Social Science Edition) ,2013, 26 (4): 676- 677.

[2] Wang yaqiong, Song E, Liao zaiyi. Post Occupancy Evaluation on Suzhou Egret Park Landscape Facilities [J] Journal of Anhui Agri. Sci, 2015, 43 (8): 170-174.

[3] Li Guoqin. Landscape Images and the Plotting of the Community Landscape [D] Beijing: Beijing Forestry University, 2004: 2-3.

[4] Yang Shiqing. An Empirical Study on Residents' Community Consciousness in Post-quake Sichuan [J] Journal of Southwest Petroleum University (Social Science Edition), 2011, 3: 49-53

[5] Deng Xue, LI Jiaming, Zeng Haojian. Research on Computation Methods of AHP Wight Vector and Its Applications [J] Mathematics in Practice and Theory, 2012, 42(7):94-95.

[6] Wang Lei. Dujiangyan Yijie district is Shanghai city that retain the old district original [N].West China Metropolis Daily, 2011-10-16.

[7] Ma Yanan, Liu Haibo, Jin Jing. Application of TOPSIS Method in the Comprehensive Evaluation of Community Health Service Center in Suburban Districts of Shenyang[J] .Chinese General Practice, 2011,14 (7A): 2148. 